Tropical Journal of Pharmaceutical Research August 2010; 9 (4): 339-346

(C) Pharmacotherapy Group,

Faculty of Pharmacy, University of Benin

Benin City, 300001 Nigeria.

All rights reserved.

Research Article

Available online at http://www.tjpr.org

\title{
Bioadhesive Controlled Release Clotrimazole Vaginal Tablets
}

\section{Sudeendra R Bhat* and HG Shivakumar}

Dept. of Pharmaceutics, JSS College of Pharmacy, JSS University, Sri Shivarathreeshwara Nagar, Mysore-570 015, Karnataka, India.

\begin{abstract}
Purpose: To formulate bioadhesive clotrimazole vaginal tablets using natural polymers in order to provide long-term therapeutic action at the site of infection.

Methods: The tablets were prepared by direct compression using bioadhesive polymer mixtures: hydroxypropyl methylcellulose/sodium carboxymethylcellulose (HPMC/NaCMC) and HPMC/Guar gum (GG) in different ratios. Differential scanning calorimetry (DSC) and Fourier transform infrared (FT-IR) spectroscopic evaluations were carried out to assess compatibility between the drug and the excipients. The tablets were subjected to various pre- and post-compression evaluations, including in vitro drug release, in vitro bioadhesive strength, swelling and stability studies.

Results: The results show that all the formulations satisfied Indian Pharmacopoeial specifications for tablet parameters. DSC and FT-IR data indicate there was no interaction between the drug and the excipients. Drug dissolution rate at $\mathrm{pH} 6.0$ followed the rank order: HPMC)/NaCMC > HPMC/GG. There was increase in swelling index with time at $37^{\circ} \mathrm{C}$. The combination of HPMC with NaCMC showed greater mucoadhesive strength and superior controlled drug release to the formulations prepared with GG polymer mixture. Furthermore, the release properties of the former in $\mathrm{pH} 6.0$ buffer, as well as release mechanism ( $n$ values), were negligibly affected by ageing.

Conclusion: This study indicates the possible use of suitable mixtures of natural and semi-synthetic cellulosic polymers for the preparation of clotrimazole mucoadhesive tablets for application as a vaginal controlled delivery system.
\end{abstract}

Keywords: Clotrimazole, Swelling, Cellulosic polymers, Guar gum, Bioadhesion, Release properties 


\section{INTRODUCTION}

Conventional vaginal drug delivery systems (e.g., pessaries, foams, creams, gels and tablets) have some limitations such as leakage, messiness and low residence time, which contribute to poor subject or patient compliance [1]. Vaginal tablets appear to be useful dosage forms as they are easy to use, portable and the required quantity of the drug can be readily administered [2,3]. Approximately $75 \%$ of women have vaginal infection with a Candida strain during their life time; about 40 to $50 \%$ of them suffer a second one, and a small percentage show a chronic course [4,5].

Clotrimazole is known to be very effective locally and presents no major side effects [6]. Hydrophilic polymers that bind to mucin or epithelial surfaces increase the residence time of the dosage form at the action or absorption site, and thus could be useful in solving bioavailability problems resulting from a too short stay of the pharmaceutical dosage form at the absorption site [7].

This study addresses the possible use of a mixture of HPMC in different ratios with $\mathrm{NaCMC}$ or $\mathrm{GG}$ for the preparation of mucoadhesive tablets of clotrimazole, a widely used antifungal agent for vaginal mycotic infections.

\section{EXPERIMENTAL}

\section{Materials}

Clotrimazole was received free of charge from Zyg Pharma Mumbai, India while sodium caboxymethylcellulose ( $\mathrm{NaCMC}$ ), hydroxypropylmethylcellulose (HPMC) and Guar Gum (GG) (all from Loba Chemie, Mumbai, India) were used as the polymers. All other chemicals were of analytical grade.

\section{Preparation of clotrimazole vaginal tablets}

Tablets containing $20 \%$ clotrimazole and weighing $500 \mathrm{mg}$ were prepared by direct compression of the formulation in a 10-station tablet machine (minipress-1674, Rimek, India) fitted with round, flat-faced $12 \mathrm{~mm}$ punches. Table 1 shows the composition of the formulations. A particle size of less than $160 \mu \mathrm{m}$ for all components was selected to avoid any fractional segregation and the formulation well mixed with a mortar and pestle to obtain a homogenous blend prior to compression

Table 1: Composition of clotrimazole mucoadhesive tablets

\begin{tabular}{|c|c|c|c|c|c|c|}
\hline \multirow{2}{*}{$\begin{array}{l}\text { Ingredient } \\
\text { (mg) }\end{array}$} & \multicolumn{6}{|c|}{ Formulation } \\
\hline & F1 & F2 & F3 & F4 & F5 & F6 \\
\hline Clotrimazole & 100 & 100 & 100 & 100 & 100 & 100 \\
\hline HPMC & 200 & 200 & 200 & 200 & 200 & 200 \\
\hline $\begin{array}{l}\text { Sodium } \\
\text { CMC }\end{array}$ & 100 & 125 & 150 & -- & -- & -- \\
\hline Guar gum & -- & -- & -- & 100 & 125 & 150 \\
\hline $\begin{array}{l}\text { Magnesium } \\
\text { stearate }\end{array}$ & 10 & 10 & 10 & 10 & 10 & 10 \\
\hline $\begin{array}{l}\text { Di-calcium } \\
\text { phosphate }\end{array}$ & 90 & 65 & 40 & 90 & 65 & 40 \\
\hline
\end{tabular}

Approx. weight of each tablet $=500 \mathrm{mg}$

\section{Evaluation of some tablet parameters}

Six tablets, randomly taken from each batch, were evaluated for hardness using a digital hardness tester (Inweka - iHT100, India). Friability studies were carried out as per USP XXVIII [8]. Twenty tablets were weighed and placed in the Roche friabilator apparatus. It was rotated at $25 \mathrm{rpm}$ for $4 \mathrm{~min}$, after which the tablets were dedusted and weighed again. Percent loss in weight was taken as friability. The weight variation test was carried out as per Indian Pharmacopoeia [9]. Twenty tablets were randomly selected from each batch and individually weighed. The mean weight and the percent deviation of each tablet were calculated. For drug content determination, three tablets, randomly taken from each batch, were powdered and an amount equivalent to $100 \mathrm{mg}$ of clotrimazole was dissolved in $100 \mathrm{mM}$ acetate buffer $(\mathrm{pH}$ 6.0) overnight using a magnetic stirrer. After filtration, the solution was assayed 
spectrophotometrically (Shimadzu-1601, Japan) for clotrimazole at $261 \mathrm{~nm}$ using 100 $\mathrm{mM}$ acetate buffer (pH 6.0) as blank.

\section{Compatibility studies}

\section{Fourier transform infrared spectroscopy (FTIR)}

The spectra were recorded for pure drug, polymer and tablet using Fourier transform infrared spectroscopy (FTIR, Shimadzu 8400 $\mathrm{S}$, Japan). Samples were prepared in $\mathrm{KBr}$ discs. The scanning wave number range was $600-4000 \mathrm{~cm}^{-1}$.

\section{Differential scanning calorimetry}

Differential scanning calorimetry (DSC) was used to assess the compatibility of clotrimazole - excipient as well as excipientexcipient compatibility [10]. DSC scans of the drug and excipients were performed, separately and in a mixed state using a Dupont 9900 thermal analyzer with a 910 DSC module. The calorimetric measurements were made with an empty cell (high purity alpha alumina discs of Dupont Company) as the reference. The scans were taken under nitrogen atmosphere over a temperature range of 25 to $330{ }^{\circ} \mathrm{C}$ and at a scan rate of $20.0^{\circ} \mathrm{C} / \mathrm{min}$.

\section{Swelling studies}

The swelling index for the tablets was determined in $100 \mathrm{mM}$ acetate buffer $(\mathrm{pH} \mathrm{6})$ at $37 \pm 0.1{ }^{\circ} \mathrm{C}$. The weight of the tablets was determined and each tablet was placed separately in a $25-\mathrm{mL}$ beaker containing 10 $\mathrm{mL}$ buffer. The beakers were stored at $37 \pm$ $0.1{ }^{\circ} \mathrm{C}$. The tablets were removed at different time intervals $(1,2,3,4,6,8,10$ and $12 \mathrm{~h})$ and weighed at each of these intervals after removing the surface water using a blotting paper. Swelling index was calculated as in Eq 2.

Swelling index $(\%)=(\mathrm{W} 2-\mathrm{W} 1) / \mathrm{W} 1 \times 100 \ldots .$.

Where where $\mathrm{W} 1$ is the original weight of the tablet before commencement of the test and
W2 is the tablet weight at each swelling interval.

\section{Bioadhesion studies}

The modified balance method [11] was adopted to measure bioadhesion properties. Isolated sheep vaginal tissue was fixed to steel piece with cyanoacrylate adhesive. This was kept in a beaker and then acetate buffer $(\mathrm{pH} \mathrm{6})$, pre-warmed to $37^{\circ} \mathrm{C}$, was added to the beaker to cover the upper surface of the mucosa in order to maintain its viability. The tablet was attached to the upper clamp with adhesive and then the beaker was slowly raised until the substrate came in contact with the tablet. A preload of $50 \mathrm{~g}$ was placed on the clamp for $5 \mathrm{~min}$ (preload time) so that adhesion can be established. After this, the preload was removed and water was added to the beaker at a constant rate of 100 drops/min. The addition of water was stopped when the bioadhesive system was detached from the mucosa. The weight required to detach the system from the mucosa was noted. The experiment was repeated 6 times with fresh mucosa in an identical manner.

\section{Drug release studies}

Drug release studies were performed using USP XXIV dissolution apparatus type II, as previously described [12], rotating at $25 \mathrm{rpm}$ and $37 \pm 0.1{ }^{\circ} \mathrm{C}$ in $500 \mathrm{~mL}$ of $100 \mathrm{mM}$ acetate buffer ( $\mathrm{pH} \mathrm{6)}$ over a $12 \mathrm{~h}$ period. The test tablet $(500 \mathrm{mg})$ was glued to the centre of a 9 $\mathrm{cm}$ diameter glass disc. Five $\mathrm{ml}$ of the sample solution was withdrawn at predetermined time intervals. An equal amount of fresh dissolution medium was used to replenish the dissolution medium immediately after the withdrawal of the test sample. The samples were analysed spectrophotometrically at 261 $\mathrm{nm}$.

\section{Evaluation of release kinetics}

In order to understand the mechanism and kinetics of drug release, the results of the in vitro drug release study were fitted to Eq 3, 
Table 2: Physicochemical characteristics (mean $\pm \mathrm{SD}$ ) of the bioadhesive tablets

\begin{tabular}{ccccccc}
\hline & \multicolumn{7}{c}{ Parameter } \\
\cline { 2 - 6 } Formulation & $\begin{array}{c}\text { Mean } \\
\text { weight } \\
(\mathbf{m g})^{\mathbf{a}}\end{array}$ & $\begin{array}{c}\text { Thickness } \\
(\mathbf{m m})\end{array}$ & $\begin{array}{c}\text { Hardness } \\
\left(\mathrm{Kg} / \mathbf{c m}^{2}\right)\end{array}$ & Friability (\%) & $\begin{array}{c}\text { Drug } \\
\text { content } \\
(\%)\end{array}$ & $\begin{array}{c}\text { Bioadhesive } \\
\text { strength }(\mathbf{g})^{\mathbf{c}}\end{array}$ \\
\hline F1 & $499 \pm 7$ & $3.3 \pm 0.2$ & $4.6 \pm 0.8$ & 0.2 & $98.3 \pm 0.2$ & $119 \pm 1$ \\
F2 & $504 \pm 6$ & $3.3 \pm 0.1$ & $5.4 \pm 0.3$ & 0.2 & $98.9 \pm 0.4$ & $125 \pm 1$ \\
F3 & $500 \pm 6$ & $3.3 \pm 0.2$ & $5.5 \pm 0.7$ & 0.2 & $99.2 \pm 0.8$ & $132 \pm 1$ \\
F4 & $499 \pm 8$ & $3.3 \pm 0.1$ & $4.8 \pm 1.0$ & 0.3 & $98.6 \pm 0.8$ & $67 \pm 1$ \\
F5 & $499 \pm 7$ & $3.3 \pm 0.2$ & $4.6 \pm 0.9$ & 0.2 & $99.3 \pm 0.7$ & $72 \pm 1$ \\
F6 & $496 \pm 5$ & $3.3 \pm 0.1$ & $5.4 \pm 0.3$ & 0.2 & $98.4 \pm 0.6$ & $82 \pm 1$ \\
\hline
\end{tabular}

${ }^{a} n=20 ;{ }^{b} n=3 ;{ }^{c} n=6$.

from which the release exponent " $n$ " was calculated [13].

$M_{t} / M_{\infty}=1-A(\exp -K t)$

where $M_{t} / M_{\infty}$ is the fraction of drug released at time $t, k$ is the kinetic constant of the system, and $n$ is the diffusional release exponent, which indicates the overall solute diffusion mechanism.

\section{Stability studies}

The stability of the formulated tablets was assessed by packing them in aluminum foil, sealed tightly and stored for 90 days at $30 \pm 2$ ${ }^{\circ} \mathrm{C}$ and $65 \pm 5 \% \mathrm{RH}$ or at $40 \pm 2{ }^{\circ} \mathrm{C}$ and $75 \pm$ $5 \% \mathrm{RH}$. The tablets were analysed for drug content and drug release on days 15, 45 and 90.

\section{Statistical data analysis}

Statistical data analysis was performed using Student $t$-test at $95 \%$ level of confidence with the aid of Microsoft Office Excel 2007.

\section{RESULTS}

\section{Tablet parameters}

The physicochemical properties of the tablets are summarized in Table 2. Mean tablet weight for all the batches was in the range of 496 - 504 mg. Thus, they all complied with the mean weight variation requirement of the Indian Pharmacopoeia [9] as no batch varied by more than $5 \%$ from the tablet weight. This indicates consistency in tablet formulation and production.

Mean hardness of the tablets $(4.6-5.5 \mathrm{~kg})$ indicates satisfactory tablet strength especially as friability was also less than $1 \%$, which complied with the requirements of USP 28 [8]. Mean drug content was $98.8 \pm 0.6 \%$ thus showing drug content uniformity of the tablets.

\section{Swelling studies}

Tablet swelling data for tablet formulations F1 to $\mathrm{F} 6$ at $37^{\circ} \mathrm{C}$ in $\mathrm{pH} 6$ acetate buffer are shown in Figure 2. Swelling after $1 \mathrm{~h}$ for the bioadhesive tablets varied between 80 and $112 \%$. Formulations made with HPMC/NaCMC showed a comparatively 
higher initial swelling than formulations made with HPMC/guar gum. Swelling of the tablets after $10 \mathrm{~h}$ varied between 164 and $180 \%$ but did not rise further with time.

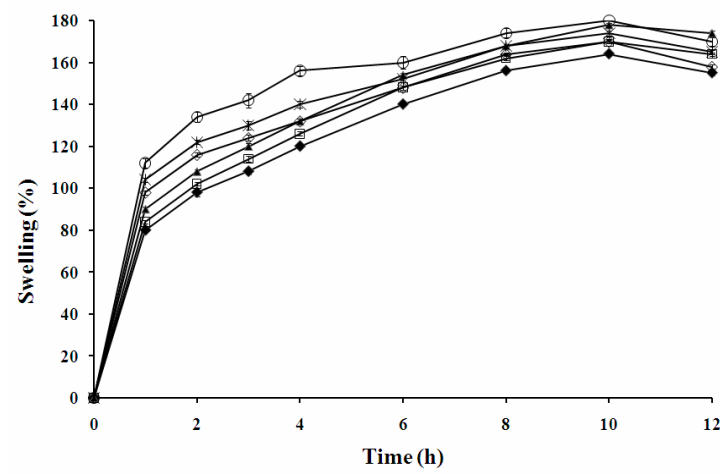

Figure 2: Swelling of tablet formulations $F$ 1

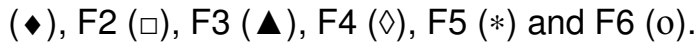
in $\mathrm{pH} 6$ acetate buffer at $37^{\circ} \mathrm{C}$

\section{Bioadhesion}

The results of the bioadhesion studies are listed in Table 2.The tablets prepared with HPMC and GG (batches F4 and F5) showed lower bioadhesive strength than those made with the combination of HPMC and NaCMC (batches F1 - F3). The force required to detach tablets containing $\mathrm{NaCMC}$ from sheep vaginal tissue was $1.77,1.74$ and 1.60 - fold greater than that for tablets containing equivalent amounts of GG.

\section{FT IR and DSC}

The IR spectra and DSC thermograms of pure clotrimazole and tablet formulations F2 and F5 are shown in Figure 1. The peak at $3450 \mathrm{~cm}^{-1}$ indicate $-\mathrm{NH}$ stretching, $2961 \mathrm{~cm}^{-1}$ for the $\mathrm{C}-\mathrm{H}$ stretching, $1564 \mathrm{~cm}^{-1}$ for the aromatic $\mathrm{N}-\mathrm{O}$ stretching, and $1266 \mathrm{~cm}^{-1}$ for the $\mathrm{C}-\mathrm{O}$ stretching. These are the major peaks of the spectra of the drug. All these peaks were present in the spectra of formulations $\mathrm{F} 2$ and $\mathrm{F} 5$ and thus this confirms the presence of the free drug in the tablet and that the drug did not interact with the excipients.

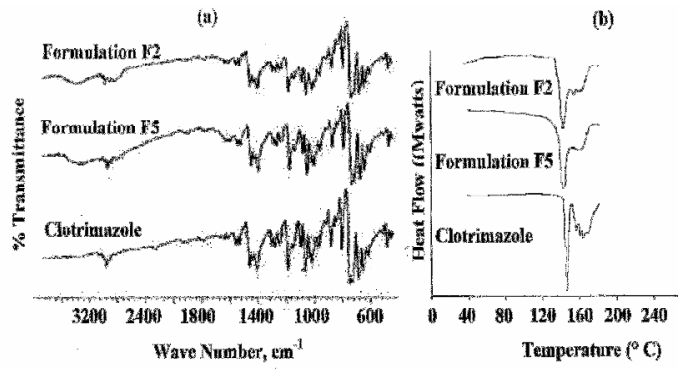

Fig 1: FTIR spectra and DSC thermograms of pure clotrimazole and tablet formulation

DSC studies of the pure drug and tablet formulations were carried out to determine if there was any interaction between the drug and the other tablet components. The thermogram of pure clotrimazole shows a sharp endothermic peak at $146{ }^{\circ} \mathrm{C}$, which corresponds to its melting point. Formulations $\mathrm{F} 2$ and $\mathrm{F} 5$ also showed endothermic peaks at 144 and $145{ }^{\circ} \mathrm{C}$, respectively, due to the presence of clotrimazole. Thus, the thermal data did not reveal any interaction between the drug and the excipients.

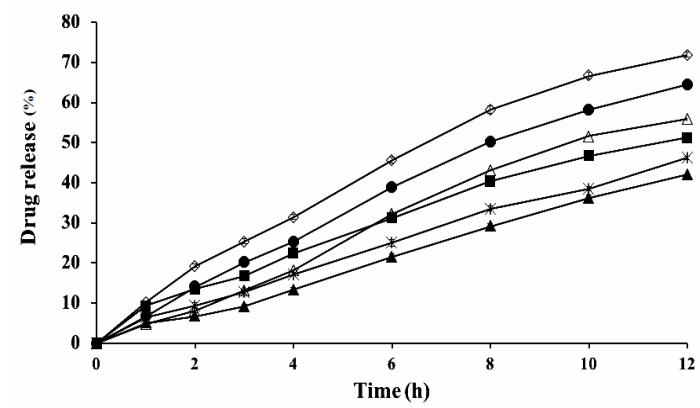

Fig 3: Effect of polymer type and ratio on the release of clotrimazole from bioadhesive vaginal

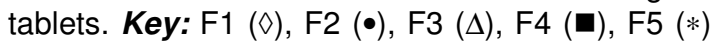
and F6 ( $\mathbf{\Delta})$

\section{Drug release}

Fig. 3 shows the drug release profiles of the tablet formulations (F1 to F6). It was observed from the data obtained that after 12 $\mathrm{h}$, the release of drug was in the rank order, $\mathrm{F} 1(71.9 \%)>\mathrm{F} 2(64.5 \%)>\mathrm{F} 3(55.8 \%)>\mathrm{F} 4$ $(51.2 \%)>$ F5 $(46.2 \%)>$ F6 (42.1\%). Thus,

Trop J Pharm Res, August 2010; 9 (4):343 
drug release from formulations made with HPMC/GG was slower that from HPMC/NaCMC polymer blends. Drug release was markedly delayed in the tablet formulation containing HPMC/GG in a ratio of $4: 3$

\section{Release kinetics}

The value found for $n$, the release exponent in the Korsemeyer-Peppas equation, was between 0.638 and 0.884 in all cases, thus indicating a non-Fickian release behavior controlled by a combination of diffusion and chain relaxation mechanism.

\section{Stability of the tablet formulations}

No statistically significant changes $(p>0.05)$ in drug content and release of the formulations occurred over the period of the stability study. Thus, the additives used did not adversely affect the stability of the drug; furthermore, the tablet formulations were physically stable.

\section{DISCUSSION}

HPMC, NaCMC and GG were chosen as bioadhesive polymers for this study because of their good swelling characteristics and have been reported to form a gel layer around drug coreand this interaction of HPMC with $\mathrm{NaCMC}$ and $\mathrm{GG}$ results in the formation of a gel on the surface of the tablet which aids in minimizing the burst effect of HPMC-based systems [14,15]. NaCMC HPMC interaction facilitates rapid formation of a viscous gel layer upon hydration and this has been regarded as an essential first step in achieving controlled drug release from matrix tablets [16].

All the tablets showed considerable swelling properties in $\mathrm{pH} 6$ medium due to the presence of hydrophilic polymers in the formulations. The swelling characteristics of a polymer contributes to its bioadhesive behaviour. To manifest maximum adhesive strength, an optimum water concentration is needed for polymer particles [17]. Polymeric matrices start to swell and build a gel layer around the tablet core when they come in contact with the medium and this feature governs drug release. HPMC, NaCMC and GG were mot only swellable polymers but also showed good mucoadhesive property. As shown in Figure 2, at the initial stage, there was an initial rapid rise in swelling index due to the entry of water via metastable pores in the polymer matrix of the tablets. This mechanism, known as swelling hysteresis, was followed by swelling caused by diffusion processes [18].

It has been reported that the presence of drug affects the property of a polymer matrix [19]. Clotrimazole is slightly soluble at $\mathrm{pH} 6.0$, and since it replaced part of the hydrophilic polymer matrix of the tablet, the wettability of the tablet surface and hence water penetration within the tablet matrix would be reduced. Formulations containing $\mathrm{NaCMC}$ showed less swelling, due probably to the formation of a protective gel layer of the polymer prior to entry of water into the matrix and hydration of the inner layers. As $\mathrm{NaCMC}$ becomes hydrated and forms a swollen gel, dissolution and surface erosion of this waterlogged gel occur simultaneously. The swelling plateau reached thereafter may be due to the solvent front on each face of the matrix meeting in the core of the tablet, leaving no additional unhydrated polymer to hydrate and expand [20]. It has also been reported that hydrogen bond interaction between NaCMC and HPMC hinders the swelling of CMC [21]. Swelling reached a peak in all the formulations after the $10^{\text {th }} \mathrm{h}$ as polymer erosion ensued.

It has been suggested by several workers that the initial interaction between a polymer and a biological surface is through electrostatic interaction followed by mechanical interlocking of the polymer chains [21]. Increasing polymer concentration caused an increase in the mucoadhesive strength. Hydration of a mucoadhesive polymer is essential to initiate the 
mucoadhesive bonding process. Mucoadhesive property was promoted by higher mucoadhesive strength due to the optimum concentration of HPMC in the formulations. The combination of HPMC and NaCMC showed greater mucoadhesive strength than HPMC/GG. HPMC a is long-chain, non-ionic polymer and its mucoadhesive property may be due to the formation of physical or hydrogen bond with mucus components of the tissue used. The tablets with higher polymer content showed greater mucoadhesive strength.

There was no initial burst effect in all the formulations. This may be due to the rapid hydration and gelation of the polymers in the tablets. The greater the content of the polymers in the formulations, the lower the release rate of the drug. It has been reported that use of HPMC in a matrix tablet as the only polymer results in a very slow release of drug due the build-up of an excessively viscous gel which is very resistant to water penetration and erosion [16]. Since the amount of HPMC used in the tablet formulations was constant, the concentration of $\mathrm{NaCMC}$ and $\mathrm{GG}$ was a significant factor in the rate of drug release. As stated earlier, formulations prepared with HPMC/GG showed a highly viscous gel around the tablet as well as a higher swelling index. Since the erosion rate of the swollen gel is slow compared with the rate of advance of the swelling front into the glassy tablet core, the diffusional path length for the drug would increase with time, thus causing the release rate to decrease. Release kinetic analysis showed that the " $n$ " value in the KorsemyerePeppas equation was between 0.5 and 1.0, thus indicating anomalous transport or case II transport. Stability studies indicate that the formulations were physically stable on ageing.

\section{CONCLUSION}

Clotrimazole vaginal tablets formed with a mixture of NaCMC and HPMC at concentrations of 40 and $20 \%$, respectively, slowly released $72 \%$ of the drug over $12 \mathrm{~h}$. Generally, the tablets exhibited good swelling and bioadhesiveness, thus promoting sustained effect in the vagina. These results also indicate that clotrimazole tablets prepared with a suitable $\mathrm{HPMC} / \mathrm{NaCMC}$ blend could be used as mocoadhesive vaginal dosage.

\section{ACKNOWLEDGEMENT}

The authors are grateful to JSS Mahavidyapeetha, Mysore and JSS University, Mysore for their in valuable support in the course of this research.

\section{REFERENCES}

1. Brannn-Peppas L. Novel vaginal drug release application. Adv Drug Delivery Rev 1993; 1: 169-177.

2. Parrott EL. Formulation of a foaming vaginal tablet and suppository. Drug Dev Ind Pharm 1998; 14: 1013-1021.

3. Kast CE, Valenta $C$, Leopold M, Bernkop-Schnürch $A$. Design and in vitro evaluation of a novel bioadhesive vaginal drug delivery system for clotrimazole. J Contr Rel 2002; 81: 347-354.

4. Ferrer J. Vaginal candidosis: epidemiological and etiological factors. Int J Gynecol Obstet 2000; 71: S21-S27.

5. Ceschel GC, Maffei P, Borgia LS, Ronchi C, Rossi $S$. Development of a mucoadhesive dosage form for vaginal administration. Drug Dev Ind Pharm 2001; 27: 541-547.

6. Ritter W, Patzschke K, Krause U, Stettendorf S. Pharmacokinetic fundamentals of vaginal treatment with clotrimazole. Chemotherapy 1982; 28: 37-42.

7. Duchene $D$, Ponchel G. Bioadhesion, a new pharmacotechnical method for improving therapeutic efficiency. STP Pharma 1989; 5: $830-838$.

8. United States Pharmacopeia 28, National Formulary 23. Rockville: United States Pharmacopeial Convention, 2005; $p 2745$ p.

9. Indian Pharmacopeia. $5^{\text {th }}$ ed. New Delhi: Controller of Publication 2007; $p 736$.

10. Kerk J, Srcic S, Urleb U, Kanalec A, Kofler B, Smid $S$, Korban J. Compatibility Study Between Acetylcysteine and Some Commonly Used Tablet Excipients. J Pharm Pharmacol 1992; 44: 515-518.

11. Rao YM. Design and evaluation of mucoadhesive drug delivery systems. Indian Drugs 1998; 35: 558-65. 
12. Amal EK, Sokar M, Naggar V, Gamal SA. Chitosan and Sodium Alginate-Based Bioadhesive Vaginal Tablets. AAPS Pharm Sci 2002; 4 (4) article 44: 1-7.

13. Paulo C, Jose MSL. Modeling and comparison of dissolution profiles. Eur J Pharm Sci 2001; 13:123-33.

14. Amal EK, Sokar M, Naggar V, Gamal SA. Bioadhesive controlled release metronidazole vaginal tablets. Acta Pharm 2002; 52: $171-$ 179.

15. Balogclu E, Zyazýcý MO, Hýzarcýogфlu SY, Karavana HA. An in vitro investigation for vaginal bioadhesive formulations:bioadhesive properties and swelling states of polymer mixtures. II Farmaco 2003; 58: 391-/396

16. Baveja SK, Rao KVR, Devi KP. Zero-order release hydrophilic matrix tablets of B-adrenergic blockers. Int J Pharm 1987; 39: 39-45.

17. Park K, Park H. Test methods of bioadhesion, in: Bioadhesive Drug Delivery Systems. Florida: CRC Press, Boca Raton: 1990; 44.
18. Carcia-Gonzalez N, Kellaway IW, Blanco-Fuente $H$. Design and evaluation of buccoadhesive metoclopramide hydrogels composed of poly (acrylic acid) cross-linked with sucrose. Int $J$ Pharm 1993; 100: 65-70.

19. Kurahashi $H$, Kami $H$, Sunada $H$, Influence of physicochemical properties on drug release rate from hydroxypropylmethylcellulose matrix tablets. Chem Pharm Bull 1996; 44: 829-832.

20. Mitchell K, Ford JL, Armstrong DJ, Elliott PNC, Hogan JE, Rostron C. The influence of drugs on the properties of gels and swelling characteristics of matrices containing methyl cellulose or hydroxypropyl-methlyl cellulose. Int J Pharm. 1993; 100: 165-173.

21. Walker CV, Wells Jl, Rheological synergism between ionic and non-ionic cellulose gums. Int J Pharm 1982; 11: 309-322.

22. Mortazavi SA, Carpenter BG, Smart JD. A comparative study on the role played by mucus glycoproteins in the rheological behaviour of the mucoadhesive/mucosal interface. Int J Pharm 1993; 94: 195-201. 